\title{
Hyperaldosteronism combined with hypercortisolaemia in a patient with adrenal carcinoma
}

\author{
N.S. Panesar, ${ }^{1}$ S.Y. Tsao, ${ }^{2}$ M.J. Wheeler ${ }^{3}$ and C.S. Cockram ${ }^{4}$ \\ Departments of ${ }^{1}$ Chemical Pathology, ${ }^{2}$ Clinical Oncology and ${ }^{4}$ Medicine, The Chinese University of Hong \\ Kong, Shatin, New Territories, Hong Kong, and ${ }^{3}$ Department of Chemical Pathology, St Thomas' Hospital, \\ London SE1 7EH, UK.
}

\begin{abstract}
Summary: A patient with adrenal carcinoma who initially presented with features suggestive of Conn's syndrome, but subsequently was shown to produce excess cortisol and other steroids, is described.
\end{abstract}

\section{Introduction}

We report on a patient with adrenal carcinoma who presented with features suggesting Conn's syndrome in whom coexistent hypercortisolaemia was subsequently demonstrated. Malignant adrenal tumours may secrete a number of different biologically active steroids and it is known that functional adrenal carcinoma producing Cushing's syndrome can also lead to virilization. ${ }^{1}$ In such patients hypercortisolaemia is more likely to be diagnosed and coincident hyperaldosteronism may be overlooked.

\section{Case report}

A 69 year old Chinese housewife presented to another hospital with a single grand mal convulsion and generalized muscle weakness in November 1984. Her blood pressure was $170 / 90 \mathrm{~mm} \mathrm{Hg}$. At presentation investigation revealed (reference ranges in parentheses): sodium (Na): $141 \mathrm{mmol} / 1$ (135-145), potassium (K): $1.6 \mathrm{mmol} / \mathrm{l} \quad(3.4-5.2)$, chloride: $84 \mathrm{mmol} / \mathrm{l}$ (95-105), bicarbonate: $33 \mathrm{mmol} / 1$ (24-31), urea: $2.8 \mathrm{mmol} / 1$ (3.3-7.0) and creatinine: $59 \mu \mathrm{mol} / \mathrm{l}$ (60-120). The urinary excretion of $\mathrm{Na}$ and $\mathrm{K}$ were $232 \mathrm{mmol}$ and $42 \mathrm{mmol}$ per 24 hours, respectively. Plasma aldosterone was $0.86 \mathrm{nmol} / \mathrm{l}$ (reference range and posture not known) and the morning and evening plasma cortisol concentrations were

Correspondence: N.S. Panesar Ph.D.

Accepted: 30 September 1987
$345 \mathrm{nmol} / \mathrm{l} \quad(200-690)$ and $226 \mathrm{nmol} / 1 \quad(<200)$, respectively. On the basis of these results Conn's syndrome was diagnosed. Treatment with spironolactone $(100 \mathrm{mg} /$ day $)$ partially corrected the hypokalaemia. Computed tomographic (CT) scanning revealed a left adrenal tumour and 2 cysts in the right kidney. A $20 \mathrm{~g}$ tumour measuring $5 \times 4 \times 3 \mathrm{~cm}$ was subsequently excised and the histological findings were reported to show a cortical adenoma with no overt features of malignancy and no vascular invasion. Postoperatively the blood pressure and plasma potassium concentration returned to normal without treatment.

In July 1985 she developed a mass on the left chest wall. Biopsy revealed metastatic carcinoma consistent with an adrenal primary. In November 1985 she was transferred to the Prince of Wales Hospital for further management. At this time her blood pressure was $180 / 90 \mathrm{~mm} \mathrm{Hg}$ on no therapy, plasma $\mathrm{K}$ was $2.7 \mathrm{mmol} / \mathrm{l}(3.5-5.1)$ and $\mathrm{Na} 146 \mathrm{mmol} / \mathrm{l}$ (134-145). The urinary $\mathrm{K}$ was $93 \mathrm{mmol} / 24$ hours. Examination revealed a hard $10 \times 8 \mathrm{~cm}$ mass over the left chest wall, $6 \mathrm{~cm}$ hepatomegaly and a mass in the left upper quadrant of the abdomen. There were no clinical features to suggest Cushing's syndrome. CT scan at this time showed a large irregular mass in the left suprarenal region involving the body wall. The left kidney was displaced and invaded by the tumour. The spleen and tail of pancreas were also possibly invaded. There were multiple hypodense areas in the liver

(C) The Fellowship of Postgraduate Medicine, 1988 
compatible with metastases. Two cysts were again noted in the right kidney and appeared benign. Further endocrinological investigation revealed the following: (i) Elevated plasma cortisol with loss of diurnal rhythm (710 nmol/1, normal 138-690, and $810 \mathrm{nmol} / \mathrm{l}$, normal $69-345$, in the morning and evening respectively). Dexamethasone ( $2 \mathrm{mg} /$ day $)$ failed to suppress morning cortisol levels (670 and $671 \mathrm{nmol} / \mathrm{l}$ before and after dexamethasone respectively). ACTH was undetectable. (ii) The supine and erect concentrations of aldosterone were $2.56 \mathrm{nmol} / 1(0.028-0.445)$ and $2.70 \mathrm{nmol} / 1(0.111-$ 0.862 ) respectively. The commercial aldosterone assay used (Diagnostic Products Corporation, Los Angeles, USA) cross-reacts only minimally with corticosterone, 18-OH-corticosterone and 11-deoxycorticosterone $(0.002 \%, 0.033 \%$ and $0.006 \%$, respectively). The plasma renin activities (PRA) were $0.55 \mathrm{ng} / \mathrm{ml} / \mathrm{h} \quad(0.12-1.59)$ and $0.70 \mathrm{ng} / \mathrm{ml} / \mathrm{h}$ (0.15-2.12) respectively. Salt loading had no effect on plasma aldosterone or PRA. (iii) The concentrations of other steroids were dehydroepiandrosterone sulphate (DHAS) $10.6 \mu \mathrm{mol} / 1(0.4$ 4.7-postmenopausal), progesterone $17 \mathrm{nmol} / 1 \quad(<5$ follicular phase), $17 \alpha-\mathrm{OH}$ progesterone $7.3 \mathrm{nmol} / 1$ (1.7-5.7-follicular phase), androstenedione $5.9 \mathrm{nmol} / 1$ (4.4-10.4-premenopausal range) and testosterone $0.9 \mathrm{nmol} / 1$ (0.8-3.2). Urinary excretion of 17-oxosteroids and 17-oxogenic steroids was $108 \mu \mathrm{mol} /$ day (20.8-52.1) and $176 \mu \mathrm{mol} /$ day $(10.4-52.1)$, respectively. Both failed to suppress with dexamethasone.

Treatment was commenced with metyrapone (with dexamethasone cover) and spironolactone. Chemotherapy was given using cisplatin and 5fluorouracil by infusion. After two courses there was regression of both the chest wall mass and the hepatomegaly and local external radiotherapy was then commenced to the tumour bulk. However, the patient's condition subsequently deteriorated and she died following an episode of pneumonia and septicaemia. Permission for post-mortem was refused.

\section{Discussion}

Although the initial presentation suggested Conn's syndrome secondary to an adrenal adenoma, subsequent events demonstrated that the adrenal tumour was malignant. This once again emphasizes

\section{References}

1. Bertagna, C. \& Orth, D.N. Clinical and laboratory findings and results of therapy in 58 patients with adenocortical tumors admitted to a single medical center (1951 to 1978). Am J Med 1981, 71: 855-874. the importance of resection of these tumours, the difficulties of making a histological diagnosis of malignancy if vascular invasion is not demonstrated, and the increased likelihood of malignancy if the tumour is large at demonstration.

Once the tumour had metastasized biochemical investigation showed excess secretion of the $\Delta^{4}$ pathway steroids - cortisol, progesterone, $17 \alpha-\mathrm{OH}$ progesterone and the $\Delta^{5}$ pathway intermediate DHAS. Androstenedione concentration would also appear to be elevated in view of the fact that there is an almost $50 \%$ decrease in androstenedione concentration following the menopause. ${ }^{2}$ Thus the urinary excretion of 17-oxosteroid and 17-oxogenic (17-OGS) steroids was elevated. Testosterone concentration, however, remained normal. In keeping with increased secretion along the $\Delta^{4}$ pathway, aldosterone concentration was also elevated.

There have been several isolated case reports describing excessive secretion of various adrenocortical steroids and intermediates in association with adrenal carcinoma. Brooks et al. ${ }^{3}$ reported a case of primary hyperaldosteronism caused by adrenal carcinoma which was found to excrete excess 17-OGS despite normal secretion of cortisol. The authors ascribed the excess 17-OGS excretion to pregnanetriol and tetrahydro-11-deoxycortisol. Filipecki et $a .^{4}$ also reported a case of adrenal carcinoma where there was an excess excretion of aldosterone and 'free corticoids'. More recently, Drury et al. ${ }^{5}$ reported two patients with adrenal carcinoma and hypercortisolaemia in both of whom secretion of corticosterone was also elevated. However, in one of these patients, PRA was raised. As with our patient neither of these patients developed clinical features of Cushing's syndrome and they presented with hypertension, hypokalaemia and encephalopathy.

Conn's syndrome secondary to adrenal carcinoma is rare. However, when the situation does arise mineralocorticoids seem to be elaborated initially, followed later by indiscriminate production of glucocorticoids ${ }^{6}$ and androgens, by the tumour. Adrenal carcinoma frequently presents with features of excess glucocorticoid and androgen secretion and evidence of excess mineralocorticoid secretion is not then usually sought. This may partially explain the apparent rarity of Conn's syndrome in association with malignant adrenal tumours.

2. Judd, H.L., Lucas, W.I. \& Yen, S.S.C. Effect of oophorectomy on circulating testosterone and androstenedione levels in patients with endometrial cancer. Am J Obstet Gynecol 1972, 118: 793-798. 
3. Brooks, R.V., Felix-Davies, D., Radcliffe Lee, M. \& Robertson, P.W. Hyperaldosteronism from adrenal carcinoma. Br Med J 1972, 1: 220-221.

4. Filipecki, S., Feltynowski, T. \& Poplawska, W. et al. Carcinoma of the adrenal cortex with hyperaldosteronism. J Clin Endocrinol Metab 1972, 35: 225-229.

5. Drury, P.L., Edwards, C.R.W., O'Hare, M.J. \& Besser,
G.M. Two cases of predominantly corticosteronesecreting adrenocortical carcinomas. J Endocrinol 1986, 108: (Suppl.) Abstract no. 271.

6. Artega, E., Biglieri, E.G., Kater, C.E., Lopez, J.M. \& Schambelan, M. Aldosterone-producing adrenocortical carcinoma. Ann Int Med 1984, 101: 316-321. 